Institute of Plant Physiology, Biological Research Center, Hungarian Academy of Sciences, Szeged, Hungary

\title{
Chilling Resistance is not Transmitted Sexually in Plants Regenerated from Nicotiana sylvestris Cell Lines
}

\author{
P. J. Dix
}

Received March 1, 1977 · Accepted March 12, 1977

\section{Summary}

Fertile plants were regenerated from three cell lines of Nicotiana sylvestris which had been selected for chilling resistance. All three lines belonged to a group exhibiting a low level of resistance. Tissue cultures initiated from the sexual progeny of these plants, however, were shown to have no improved level of chilling resistance when compared to cultures derived from unselected control plants.

Key words: chilling resistance, cell lines, plant regeneration, acclimation.

\section{Introduction}

As reported in an earlier paper (Dix and STREeT, 1976), cell lines with enhanced chilling resistance could be selected from haploid or diploid cell cultures of Nicotiana sylvestris. These cell lines were subsequently divided into two groups; one, represented by only two cell lines, with a high degree of resistance, and the other with a low degree of resistance, as assessed by the recovery of callus pieces subjected to a mild chilling treatment $\left(0^{\circ} \mathrm{C}\right.$ for 21 days), or by the effect on colony formation, from plated suspension cultures, of a more severe chilling treatment $\left(-3^{\circ} \mathrm{C}\right.$ for 21 days $)$ (Dix and STREET, 1976). In order to decide whether resistance is due to mutation or physiological cold acclimation, studies on the inheritance of chilling resistance were desirable.

Extensive manipulation of the culture conditions failed to yield plants from the two strongly resistant cell lines. From three of the twenty cell lines with a low degree of resistance, fertile flowering plants were obtained. Experiments on the chilling resistance of cultures derived from the progeny of these plants, are reported in this paper.

\section{Materials and Methods}

Shoot formation from the cell lines was induced by transfer of callus pieces from the usual culture medium (that of Linkmaier and Skoog, [1965], containing $0.4 \mathrm{mg} \mathrm{I}^{-1} 2,4-\mathrm{D}$, $0.03 \mathrm{mg} \mathrm{l}^{-1}$ kinetin, and solidified with $0.8 \%$ "Difco" bactoagar) to the same medium, from which 2,4-D and kinetin had been omitted. Shoots were rooted by transfer to the T medium of NiTsCH and NiTsCH (1969). The flowers were selfed and their seeds collected for use in subsequent investigations. 
Seeds were surface sterilized in $5 \%$ hypochlorite for ten minutes and germinated on $0.8 \%$ $\operatorname{agar}(\mathrm{w} / \mathrm{v})$.

Callus cultures were initiated from leaf sections on the LINSMAIER and SKoog medium described above, and suspension cultures initiated and maintained as described previously (Dix and StREET, 1974).

Callus cultures were tested for chilling resistance in the form of small pieces $(0.025$ to $0.050 \mathrm{~g}$ ) on the surface of agar medium in petri dishes. Suspension cultures (7-10) days after subculture) were filtered through $1 \mathrm{~mm}$ mesh nylon bolting cloth, incorporated into agar medium, melted and held at $38^{\circ} \mathrm{C}$, and inoculated into sterile petri dishes $(10 \mathrm{ml}$ per dish) to give a final cell density of $20 \times 10^{3}$ cells $\mathrm{ml}^{-1}$. Cell densities were determined according to Henshaw et al. (1966). The plates were sealed and incubated at $25^{\circ} \mathrm{C}$ for 5 days, prior to exposure to the chilling conditions. Plates containing callus pieces or filtered cell suspensions were subjected to chilling conditions for 21 days, and returned to $25{ }^{\circ} \mathrm{C}$ where they were maintained for 6 weeks, at which time callus pieces were weighed, and colonies from suspension cultures counted. For further details of these methods, which closely resemble the original selection procedure, see Dix and Street (1976).

\section{Results and Discussion}

Table 1 compares the effect of the milder chilling treatment $\left(21\right.$ days at $\left.0^{\circ} \mathrm{C}\right)$ on callus pieces from the original lines which have been maintained continuously as callus cultures, or have been freshly initiated from the progeny of regenerated plants. On Table 2 is presented a similar comparison, for the effects of the more severe chilling reatment $\left(21\right.$ days at $\left.-3{ }^{\circ} \mathrm{C}\right)$ on the colony formation by plated suspension cultures. In both tables NV 6, NV 13 and NV 23 represent the three variant lines and $\mathrm{H} 9$ and $\mathrm{D}$ represent non-selected haploid-derived and diploid-derived material, respectively.

All three variant callus lines showed a marked improvement over non-selected lines, in recovery from a 21 day exposure to $0^{\circ} \mathrm{C}$. This improvement probably re-

Table 1: Comparison of chilling resistance of NV 6, NV 13 and NV 23 resistant callus, and callus obtained from the seedlings of their regenerates.

\begin{tabular}{lcccccc}
\hline & \multicolumn{3}{c}{ Original line } & \multicolumn{3}{c}{ Regenerate line } \\
& $\begin{array}{c}\text { mean fresh } \\
\text { weight }(\mathrm{g})\end{array}$ & SEM & $\begin{array}{c}\text { Number of } \\
\text { replicates }\end{array}$ & $\begin{array}{c}\text { mean fresh } \\
\text { weight }(\mathrm{g})\end{array}$ & SEM $\left.^{*}\right)$ & $\begin{array}{c}\text { Number of } \\
\text { replicates }\end{array}$ \\
\hline NV 6 & 0.523 & 0.028 & 30 & 0.303 & 0.016 & 50 \\
NV 13 & 0.392 & 0.028 & 30 & 0.102 & 0.010 & 50 \\
NV 23 & 0.670 & 0.040 & 30 & 0.248 & 0.018 & 40 \\
$\mathrm{H}_{9}$ & 0.205 & 0.015 & 30 & 0.285 & 0.022 & 45 \\
D & 0.224 & 0.020 & 30 & 0.227 & 0.011 & 50
\end{tabular}

*) SEM = Standard error of the mean

$\mathrm{H}_{9}$ and $\mathrm{D}$ designate cultures initiated from unselected haploid and diploid plants respectively. Chilling resistance is assessed by recovery of callus pieces after exposure to $0^{\circ} \mathrm{C}$ for 21 days, and scored as mean fresh weight (g) 6 weeks after removal from the chilling conditions.

Initial weight of callus pieces was $0.025-0.050 \mathrm{~g}$. 
flects a higher proportion of the callus contributing to renewed growth. In the nonselected lines re-growth was mainly sectorial and often from very small regions of the callus. Only NV 23 however, shows a clear enhancement of resistance when subjected as a plated cell suspension, to $-3{ }^{\circ} \mathrm{C}$ for 21 days. These three lines are termed «low» in resistance as two other lines, NV 14 and NV 35 (Dix and Street, 1976), exhibited emphatically greater resistance (e.g. $32.3 \%$ and $43.9 \%$, respectively, of colony production in the plating test) in such tests.

The cultures obtained from the progeny of selfed plants no longer show any enhanced resistance over non-selected lines in either callus (Table 1) or plating tests (Table 2). The low level of chilling resistance appears to have been lost.

Table 2: Comparison of resistance after a severe chilling treatment, of plated suspensions of NV 6, NV 13 and NV 23 resistant lines, and lines obtained from the seedlings of their regenerates.

\begin{tabular}{|c|c|c|c|c|}
\hline & \multicolumn{2}{|c|}{ Original line } & \multicolumn{2}{|c|}{ Regenerate line } \\
\hline & mean & SEM & mean & SEM \\
\hline NV 6 & 8.2 & 0.9 & 0.8 & 0.4 \\
\hline NV 13 & 5.6 & 0.6 & 4.8 & 1.1 \\
\hline NV 23 & 16.9 & 1.7 & 2.5 & 0.6 \\
\hline $\mathrm{H}_{9}$ & 1.8 & 0.5 & 3.2 & 0.8 \\
\hline $\mathrm{D}$ & 4.9 & 1.1 & 1.1 & 0.4 \\
\hline
\end{tabular}

Resistance is assessed by colony formation on plates after exposure to $-3{ }^{\circ} \mathrm{C}$ for 21 days. Initial plating density was $20 \times 10^{3}$ cells $\mathrm{ml}^{-1}$. The values are the numbers of colonies observed 6 weeks after removal from the chilling conditions, expressed as a percentage of the number of colonies counted after 6 weeks on plates which had not been exposed to chilling conditions (always between 120 and 220 colonies plate $^{-1}$ ), and represent the mean of 10 replicates.

For further details see legend to Table 1.

There are two possible interpretations of the data. Firstly the resistance may result from an epigenetic, rather than a genetic, change (Maliga, 1976). Epigenetic changes have already been invoked as the basis of cycloheximide resistance in a tobacco cell line (Malrga et al., 1976), but the present situation differs in that resistance is stable in culture, through long periods in the absence of the selective pressure. A low level of chilling resistance in plant cell cultures is more comparable with auxin or cytokinin habituation, other cellular phenotypes which are lost only on plant regeneration (Melchers, 1971; Meins, 1974).

The alternative interpretation is that the callus may have been chimeric, sensitive cells being able to persist through selection and subsequent culture, in close connection with the resistant callus. These cells may have proved more amenable to plant regeneration, giving rise to sensitive plants. Limited data on the resistance of callus derived from the regenerants (DIx, 1975) suggest that resistance has been reduced, 
but not completely lost, on plant regeneration. The implication is that resistant callus has at least contributed to plant regeneration.

Low level chilling resistance may be induced by the chilling procedure in a process related to the cold acclimation of woody species (WEISER, 1970). Chilling sensitive species can, in some cases, be conditioned against chilling injury (Lyons, 1973), and a similar routine physiological process could be responsible for the resistance of certain cells in $N$. sylvestris cultures. The marked differences in resistance however, between lines of «low» and «high» resistance, suggest that a genetic basis for the latter cannot be excluded.

\section{Acknowledgements}

I thank Professor H. E. Street and Dr. L. H. Jones for their interest in the earlier stages of the work and Dr. P. Maligs for suggestions and constructive criticism of the manuscript. The work was commenced during the tenure of a Science Research Council studentship and terminated while the author was a Research Fellow working within the UNDP project HUN/71/506. Part of the research was supported by OMFB grant No. $79978 / 28 / 22-2764$.

\section{References}

Dix, P. J.: Plant Cell lines Resistant to Environmental Stresses. Ph. D. thesis (1975).

Dix, P. J., and H. E. StreEt: Effects of p-Fluorophenylalanine (PFP) on the growth of cell lines differing in ploidy and derived from Nicotiana sylvestris. Pl. Sci. Lett. 3, 283-288 (1974).

Dix, P. J., and H. E. Street: Selection of Plant Cell Lines with Enhanced Chilling Resistance. Ann. Bot. 40, 903-910 (1976).

Henshaw, G. G., K. K. Jha, A. R. Mehta, D. I. Shakeshaft, and H. E. Street: Studies on the growth in culture of plant cells. I. Growth patterns in batch propagated suspension cultures. J. Exp. Bot. 17, 362-377 (1966).

Linsmaier, E. M., and F. Skoog: Organic growth factor requirements of tobacco tissue cultures. Physiol. Plantarum 18, 100-127 (1965).

Lyons, J. M.: Chilling Injury in plants. Ann. Rev. Plant Physiol. 24, 445-466, (1973).

Maliga, P.: Isolation of mutants from cultured plant cells. In: D. Dudits, G. L. Farkas, and P. Maliga (Eds.): Cell Genetics in Higher Plants. pp. 59-76. Publishing House of the Hungarian Academy of Sciences, Budapest, 1976.

Maliga, P., G. LÁzár, Z. Sváb, and F. Nagy: Transient Cycloheximide Resistance in a Tobacco Cell Line. Molec. Gen. Genet. 149, 267-271 (1976).

MeINs, F.: Mechanisms underlaying the persistance of tumor autonomy in crown gall diseases. In: H. E. Street (Ed.): Tissue culture and plant science. pp. 233-264. Academic Press, London-New York-San Francisco, 1974.

Melchers, G.: Transformation or habituation to autotrophy and tumor growth and recovery. In: Les cultures de tissues de plantes, pp. 229-234, Paris: Colloq. Inter. C. N. R. S. No. 193, Editions du Centre Nat. Rech. Scient. (1971).

Nitsch, J. P., and C. Nitsch: Haploid plants from pollen grains. Science 163, 85-86 (1969).

WEISER, C. J.: Cold resistance and injury in woody Plants. Science 169, 1269-1278 (1970).

Dr. P. J. Drx, Institute of Plant Physiology, Biological Research Center, Hungarian Academy of Sciences, 6701 Szeged, P.O. Box 521, Hungary.

Z. Pflanzenphysiol. Bd. 84, S. 223-226, 1977. 